Check for updates

Cite this: RSC Adv., 2019, 9, 16147

\title{
Use of sodium alginate in the preparation of gelatin-based hard capsule shells and their evaluation in vitro
}

\author{
Sahar Abbasiliasi, (D)*a Tan Joo Shun, (D) ${ }^{\text {b }}$ Tengku Azmi Tengku Ibrahim, ${ }^{\text {cd }}$ \\ Nurdiana Ismail, ${ }^{a}$ Arbakariya B. Ariff, (D) e Nurfadhilah Khairil Mokhtar ${ }^{a}$ \\ and Shuhaimi Mustafa (D) *af
}

Using only type B gelatin produces hard capsule shells which are too brittle. This study examines the blending of type B bovine gelatin with sodium alginate to produce hard capsule shells and through evaluation of their in vitro physicochemical properties provides a reflection on the role of gelatin and sodium alginate in the blend. The compositions and formulation of the capsule shells in this study comprised gelatin $(10 \%, 20 \%$ and $30 \%)$, sodium alginate $(1 \%, 2 \%, 3 \%, 4 \%$ and $5 \%)$, water, and opacifying agents (titanium dioxide; $\mathrm{TiO}_{2}$ ) and polyethylene glycol (PEG) whose concentrations were kept constant. From the 15 films prepared, five were found to form hard capsule shells. Increased concentrations of sodium alginate increased the viscosity of the blends accompanied by capsule thickening. There was a good molecular compatibility between gelatin and sodium alginate. Increased gelatin and sodium alginate concentrations increased the water-holding capacity of the film, which decreased the redness $\left(a^{*}\right)$, lightness $\left(L^{*}\right)$, blueness $\left(b^{*}\right)$, variation in the color parameters $\left(\Delta E^{*}\right)$ and the whiteness index $(\mathrm{WI})$. The weight of the capsule shells ranged between $0.080 \mathrm{~g}$ and $0.25 \mathrm{~g}$ and the moisture content was between $5 \%$ and $11 \%$. Ash contents for all the formulations were below $5 \%$ and the sensitivity of capsules at $\mathrm{pH} 7$ was higher than that at acidic $\mathrm{pH}$. Highest rupture times were observed with simulated gastric fluid (SGF, pH 1) for all formulations. Increased gelatin concentration decreased the resistance of the capsule to force while increased sodium alginate concentration had no effect on resistance to force.

\author{
Received 8th March 2019 \\ Accepted 8th May 2019 \\ DOI: 10.1039/c9ra01791g \\ rsc.li/rsc-advances
}

In hard capsule production, reversible gel formation by hydrogen bonding at low temperature appears to be the most important property of the gelatin. This is attributed to the fact that at body temperature, gelatin is readily soluble in biological fluids, leading to the formation of a thermoreversible gel. ${ }^{2}$ Further, it possesses good film properties, so it could be dissolved in gastric juices while maintaining its durable and resilient properties to withstand manipulation during filling and transportation. ${ }^{3}$ In spite of the above excellent properties, gelatin is not without drawbacks, including filled component reactivity, ${ }^{4}$ anionic:cationic polymer interaction, ${ }^{5}$ a low humidity environment leading to brittleness, reaction to certain drugs and excipients, and not being compatible with certain hygroscopic materials. ${ }^{6}$ From the perspective of in vitro and in vivo release, gelatin capsules are further disadvantaged by the cross-linking reaction. This disadvantage invariably occurs under conditions of accelerated storage and at times is facilitated by other drugs and excipients. ${ }^{7}$ Cross linking also contributes to a reduction in the water solubility of the gelatin, which will invariably be followed by disintegration of the capsule shell, resulting in reduced drug release. ${ }^{8}$ 
In the search for alternatives to synthetic polymers, polysaccharides and proteins which are polar biopolymers, have been investigated. Both have gained considerable attention in the biomedical and pharmaceutical industries in view of their almost comparable physical properties with that of gelatin, apart from their biocompatible and biodegradable natures. ${ }^{9}$ Moreover, the above are readily available, costeffective and harmless to the environment. Although polysaccharide-based films coupled with plasticizers are superior to protein-based films from the perspective of an oxygen barrier, it has been reported that the latter have superior mechanical properties. ${ }^{\mathbf{1 0}}$ Studies on sodium alginate and gelatin directed towards the above alternatives have been rather limited but nevertheless resulted in film-forming characteristics. Additionally, their mechanical and physical properties conformed to the requirements of hard capsule shells. From the perspective of drug formulation, naturally occurring alginate polymers have a wide potential attributed principally to their extensive application as food additives and to a lesser extent to their lack of toxicity. Thus alginates could be formulated to fulfil the requirements of both pharmaceutical and biomedical needs. The characteristics of this group of polymers present themselves as a useful formulation aid to cater for the need for a conventional excipient and more specifically as a tool in polymericcontrolled drug delivery. ${ }^{11}$ Since it is a bio-erodible natural polymer, the application of sodium alginate has been directed towards the controlled release of drugs and pesticides, attributed principally to its strong gel formation in aqueous media. ${ }^{12}$ Structurally, sodium alginate is a linear block copolymer of 1-4 linked $\beta$-D-mannuronic acid and $\alpha$-Lguluronic acid with commendable film-forming ability. A derivative of collagen and being a natural protein, gelatin is a heterogeneous product made up of a, b and c peptides. Being nontoxic, biocompatible and biodegradable at body temperature makes it ideal for pharmaceutical applications. ${ }^{13}$ Blending sodium alginate and gelatin resulted in the formation of a compound with improved mechanical properties and water absorptivity. The above combination resulted in the formation of functional polymers with a markedly improved performance. It could be the strong intermolecular hydrogen bonds and ionic interaction in the blending of films of sodium alginate and gelatin which enhanced their mechanical properties. Blending is an effective method for improving the performance of films. With two compatible components, the blended film produced a homogeneous structure and demonstrated improved performance compared to that of the individual components. ${ }^{\mathbf{1 4}}$

A number of reports have been published on the use of sodium alginate in the preparation of calcium-induced alginate gel beads ${ }^{\mathbf{1 5 - 1 7}}$ in the manufacture of verapamil matrix tablets, alginate-based prolonged release theophylline tablets $^{\mathbf{1 8}}$ and suspensions ${ }^{\mathbf{1 9}}$ and the use of sodium alginate in microencapsulation to achieve prolongation of drug release. ${ }^{\mathbf{2 0 , 2 1}}$ However, reports on the use of sodium alginate in the formulation of hard capsule shells are rather limited. Thus, the objective of this study is directed towards the production of sodium alginate-gelatin based hard capsule shells and an evaluation of their physical and mechanical properties in vitro.

\section{Materials and methods}

\subsection{Supplies}

Commercial grade sodium alginate $\left(\mathrm{C}_{6} \mathrm{H}_{9} \mathrm{NaO}_{7}\right)$, titanium dioxide $\left(\mathrm{TiO}_{2}\right)$ and polyethylene glycol (PEG, molecular weight $400 \mathrm{~g} \mathrm{~mol}^{-1}$ ) were sourced from R \& M Marketing (Essex, UK). Bovine gelatin type $\mathrm{B}$ and pepsin from porcine stomach mucosa were obtained from Sigma-Aldrich (St. Louis, USA). Analytical grades of all chemicals were used in this study.

\subsection{Preparation of gelatin-alginate base mixture, hard capsule shell formation and film casting}

Gelatin-sodium alginate solution was prepared using blends of gelatin-alginate, plasticizer (PEG $400 \mathrm{~g} \mathrm{~mol}^{-1}$ ) and opacifying agent (titanium dioxide, $\mathrm{TiO}_{2}$ ). Mixtures with different proportions of gelatin $(10-30 \% \mathrm{w} / \mathrm{v})$ and sodium alginate $(1-5 \% \mathrm{w} / \mathrm{v})$ were prepared. Gelatin-sodium alginate solution was formulated with the concentrations of PEG $(5 \%$ $\mathrm{w} / \mathrm{v})$ and $\mathrm{TiO}_{2}(0.2 \% \mathrm{w} / \mathrm{v})$ being kept constant while concentrations of gelatin $(10-30 \% \mathrm{w} / \mathrm{v})$ and sodium alginate $(1-5 \%$ $\mathrm{w} / \mathrm{v}$ ) were varied.

The mixtures were dissolved in hot deionized water $(70 \pm 2$ ${ }^{\circ} \mathrm{C}$ ) until a clear solution was obtained. $\mathrm{pH}$ values of every formulation were recorded. To prepare the capsules, prior to the dipping process the stainless steel pins were heated to $70{ }^{\circ} \mathrm{C}$ to ensure uniformity on the mould pin. Following the method by ref. 3 the stainless steel pins were lowered into the warm solutions, and immediately withdrawn from the solution when the film set, to form empty bodies which were allowed to dry overnight at room temperature. The dried capsules were removed, trimmed to a length comparable to size 0 of a standard capsule (overall closed length: $\sim 21.6 \mathrm{~mm}$, empty capsule individual cap length: $\sim 10.85 \mathrm{~mm}$, and empty capsule individual body length: $\sim 18.35 \mathrm{~mm}$ ) and weighed. Formulations of the capsule preparation are shown in Table 1. Five measurements were taken for each formulation and the average values recorded. For formation of gelatin-sodium alginate film strips, a defined volume of homogeneous gelatin-sodium alginate solution was poured into a glass Petri dish and spread evenly using a glass rod which was equal to $\sim 0.1-0.2 \mathrm{~mm}$ in plate height. The plates were then dried at ambient temperature for $24 \mathrm{~h}$ and the films were peeled off from the plate, cut into $5 \mathrm{~cm} \times 5 \mathrm{~cm}$ squares and stored at $53 \pm 1 \% \mathrm{RH}$ and $25 \pm 1{ }^{\circ} \mathrm{C}$ in desiccators for subsequent use. ${ }^{22}$

\subsection{Rheological characteristic of base mixture}

The steady shear measurements of dispersions in gelatin solution, alginate solution and gelatin-alginate solution were carried out using an AR-G2 rheometer (TA Instruments, Essex, England) which interfaced with texture analyzer 
Table 1 Base mixture formulation and properties ${ }^{a}$

\begin{tabular}{|c|c|c|c|c|c|c|c|}
\hline Film code & Gltn $(\% \mathrm{w} / \mathrm{v})$ & $\mathrm{SA}(\% \mathrm{w} / \mathrm{v})$ & PEG $400(\% \mathrm{w} / \mathrm{v})$ & $\mathrm{TiO}_{2}(\% \mathrm{w} / \mathrm{v})$ & Capsule formation & $\mathrm{pH}$ & Moisture content (\%) \\
\hline (Control) & 10 & 0 & 5 & 0.2 & No & - & - \\
\hline $\mathrm{F}_{1}$ & 10 & 1 & 5 & 0.2 & No & $5.45 \pm 0.02$ & $12.89 \pm 0.09$ \\
\hline $\mathrm{F}_{3}$ & 10 & 3 & 5 & 0.2 & No & $5.47 \pm 0.04$ & $10.24 \pm 0.01$ \\
\hline $\mathrm{F}_{4}$ & 10 & 4 & 5 & 0.2 & Yes & $5.57 \pm 0.04$ & $9 \pm 0.14$ \\
\hline $\mathrm{F}_{5}$ & 10 & 5 & 5 & 0.2 & No & $5.73 \pm 0.04$ & $8.22 \pm 0.02$ \\
\hline $\mathrm{F}_{7}$ & 20 & 2 & 5 & 0.2 & Yes & $5.66 \pm 0.06$ & $12.92 \pm 0.01$ \\
\hline $\mathrm{F}_{8}$ & 20 & 3 & 5 & 0.2 & Yes & $5.60 \pm 0.08$ & $11.72 \pm 0.05$ \\
\hline $\mathrm{F}_{9}$ & 20 & 4 & 5 & 0.2 & No & $5.72 \pm 0.08$ & $10.86 \pm 0.10$ \\
\hline $\mathrm{F}_{10}$ & 20 & 5 & 5 & 0.2 & No & $5.81 \pm 0.03$ & $10.55 \pm 0.02$ \\
\hline (Control) & 30 & 0 & 5 & 0.2 & Yes & - & - \\
\hline $\mathrm{F}_{11}$ & 30 & 1 & 5 & 0.2 & Yes & $5.66 \pm 0.10$ & $14.55 \pm 0.15$ \\
\hline
\end{tabular}

rheology advantage data analysis software (version V5.7.0). A $40 \mathrm{~mm}$ diameter geometry with a $61 \mathrm{~mm}$ gap was used to monitor viscosity at shear rates of $0.1 \mathrm{~s}^{-1}$ to $1000 \mathrm{~s}^{-1}$ at $60{ }^{\circ} \mathrm{C}$.

\subsection{Determination of functional groups of base mixture}

A Nicolet 6700 Fourier transform infrared spectrometers (FTIR; Thermo Nicolet Corp., Madison, WI, USA) equipped with an OMNIC operating system (Version 7.0 Thermo Nicolet) was used to identify the functional group and structural elucidation according to the procedure of ref. 23 with some modifications. Spectra of base mixtures were recorded with a resolution of $4 \mathrm{~cm}^{-1}$, accumulating 16 scans per spectra. The spectra were recorded from 4000 to $400 \mathrm{~cm}^{-1}$. Spectrum acquisition of each sample was repeated thrice under the same conditions and an average spectrum obtained. A background deionized water spectrum was used as blank, which was scanned before measurement. Gelatin was used as the standard reference.

\subsection{Determination of water-holding capacity of film}

Water-holding capacity (WHC) was determined as described by ref. 24 with some modifications. $10 \mathrm{~mL}$ of distilled water was added to $0.5 \mathrm{~g}$ of film samples, held at ambient temperature for $1 \mathrm{~h}$ and vortexed for $5 \mathrm{~s}$ every $20 \mathrm{~min}$. Following centrifugation at $2800 \mathrm{~g}$ for $20 \mathrm{~min}$, the solution was filtered with Whatman No. 1 filter paper. The difference between the initial volume of distilled water added to the sample and the final volume was determined. Results were reported as volume $(\mathrm{mL})$ of water absorbed per weight $(\mathrm{g})$ of sample. ${ }^{25}$ The test was carried out in triplicate. WHC was calculated using eqn (1):

$$
\text { water-holding capacity }(\mathrm{WHC})=\frac{V_{0}(\mathrm{~mL})-V_{1}(\mathrm{~mL})}{W(\mathrm{~g})}
$$

where: $V_{0}=$ initial volume of distilled water, $V_{1}=$ final volume of solution and $W=$ weight of sample (g).

\subsection{Color value determination of film}

A Hunter Lab colorimeter (Color Flex, Hunter Lab Inc., Reston, VA, USA) was used to determine the color values of the film. $L$ (lightness/brightness), $a$ ( $+a$ : redness/- $a$ : greenness) and $b(+b$ : yellowness/- $b$ : blueness) values expressed the film color. Five measurements (one at the centre and four around the perimeter) were taken on each film and the mean values recorded. The whiteness index (WI) and total difference in color $\left(\Delta E^{*}\right)$ were calculated according to eqn (2) and (3), respectively, as suggested by ref. 26 .

$$
\begin{gathered}
\mathrm{WI}=L-3 b \\
\Delta E=\sqrt{\left(L_{\mathrm{R}}-L_{\mathrm{S}}\right)^{2}+\left(a_{\mathrm{R}}-a_{\mathrm{S}}\right)^{2}+\left(b_{\mathrm{R}}-b_{\mathrm{S}}\right)^{2}}
\end{gathered}
$$

where subscripts R and S represent the Hunter color values for the reference and sample, respectively.

\subsection{Physical properties of capsule and film}

2.7.1. Moisture content. The moisture content percentages of each capsule and film were evaluated using the loss on drying method. ${ }^{27}$ Briefly, $5 \mathrm{~g}$ of the samples were dried at $105{ }^{\circ} \mathrm{C}$ to obtain a constant weight. The moisture contents of capsules and films were calculated based on the weight difference before and after drying using eqn (4):

$$
\text { moisture }(\%)=\frac{W_{1}(\mathrm{~g})-W_{2}(\mathrm{~g})}{W_{1}(\mathrm{~g})} \times 100
$$

where: $W_{1}=$ initial weight of sample $(\mathrm{g})$ and $W_{2}=$ final weight of sample (g). 

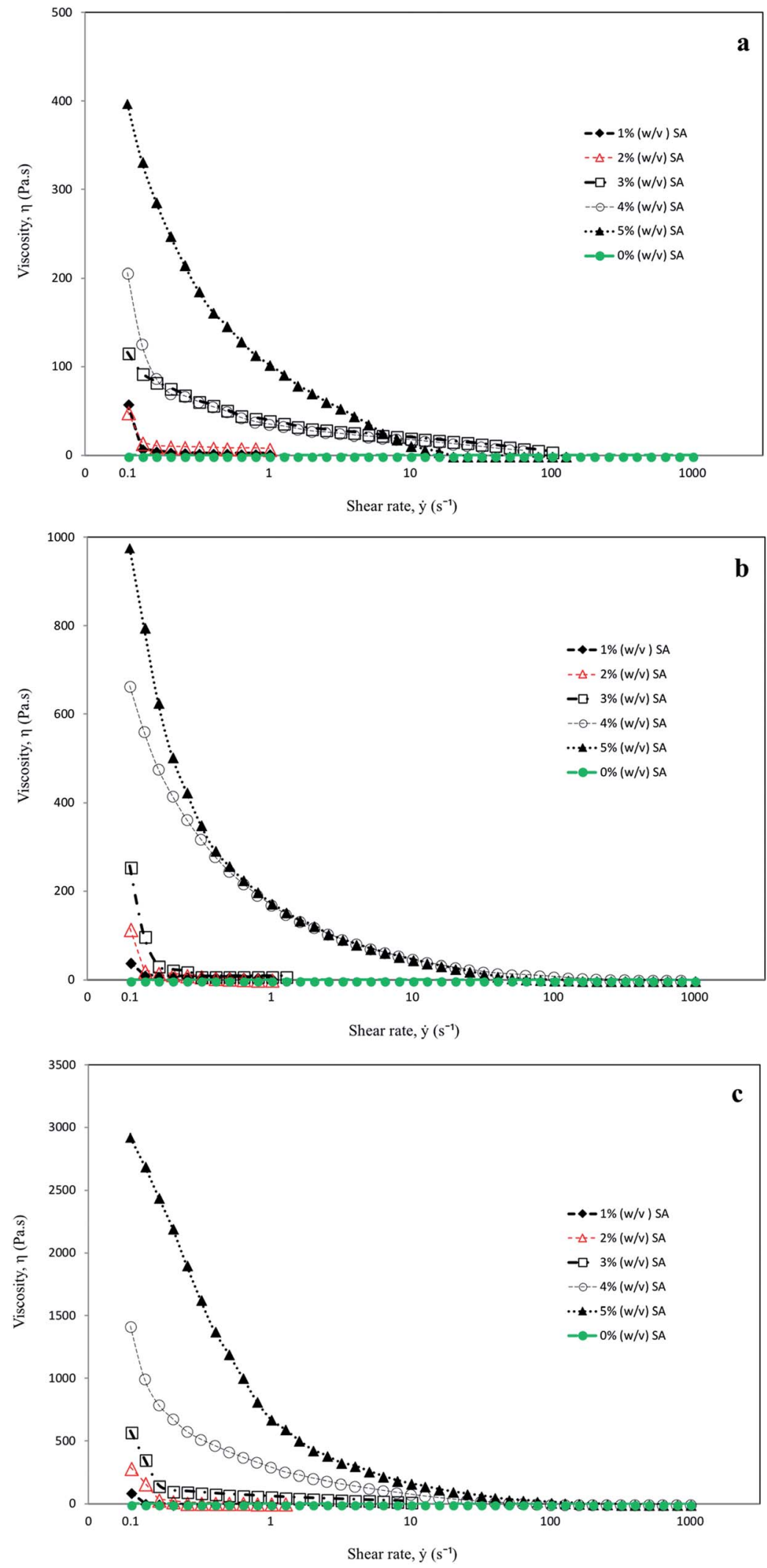

Fig. 1 Viscosity profiles of (a) 10\%; (b) 20\%; and (c) 30\% gelatin with different concentrations of sodium alginate.

2.7.2. Ash content. Ash content was determined according to the method of the Association of Official Analytical Chemists. ${ }^{27} 5 \mathrm{~g}$ of the sample was incinerated at $550{ }^{\circ} \mathrm{C}$ in a Carbolite ashing furnace (Keison products, Essex, UK) to obtain a constant weight. Percentage of ash content was calculated based on weight difference before and after incineration using eqn (5): 


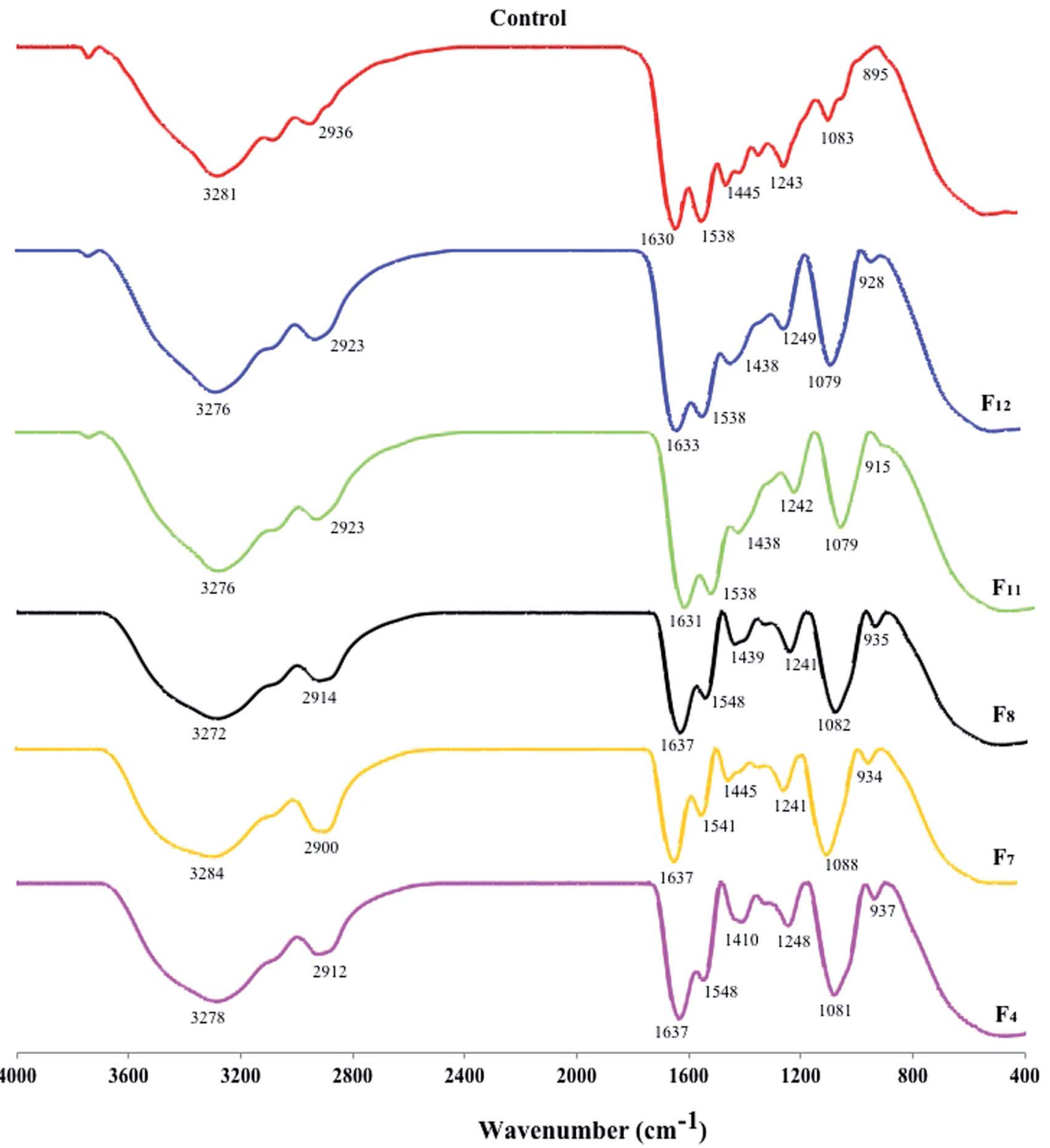

Fig. 2 FTIR spectra of gelatin (G) and gelatin-sodium alginate blends (formulations 4, 7, 8, 11 and 12) with the ability to produce capsules.

$$
\operatorname{ash}(\%)=\left(W_{1}-W_{2}\right) \times 100
$$

where: $W_{1}=$ initial weight of sample $(\mathrm{g})$ and $W_{2}=$ final weight of sample (g).

2.7.3. Weight and thickness. Shell weight and thickness were measured with a digital balance and micrometer, respectively. Five different positions were taken randomly and the precision of the thickness measurements was $\pm 5 \%$.

\subsection{Capsule shell rupture time evaluation}

The capsule shell rupture time was evaluated by the procedure described by ref. 28 with some modifications. One capsule was placed in a $100 \mathrm{~mL}$ conical flask and to it were added $50 \mathrm{~mL}$ each of acetate buffer ( $\mathrm{pH}, 4.5)$, phosphate buffer ( $\mathrm{pH}$ 6.8), and simulated gastric fluid (SGF). The mixture was stood in a water bath with constant agitation at $37{ }^{\circ} \mathrm{C} \pm 2$. SGF was prepared by adding $9 \mathrm{~g} \mathrm{~L}^{-1}$ of sodium chloride $(\mathrm{NaCl})$ and $3 \mathrm{~g} \mathrm{~L}^{-1}$ pepsin from porcine stomach mucosa (Sigma-Aldrich, St. Louis, MO, USA) adjusted to $\mathrm{pH} 1.2$ with $1 \mathrm{M}$ hydrochloric acid, as described by ref. 29. The mixture was filtered under sterile conditions through a $0.45 \mu \mathrm{m}$ nylon filter membrane (SigmaAldrich, St. Louis, MO, USA). Empty capsules were suspended in the above solution and the time taken for the capsule to burst was recorded.

\subsection{Capsule shell strength determination}

Characterization of capsule stiffness was obtained from texture profiles using a texture analyzer TA-XT2 from Stable Micro Systems (Surrey, UK). Size 0 gelatin-sodium alginate capsules were compressed with a platen up to $1.2 \mathrm{~mm}$ displacement with 


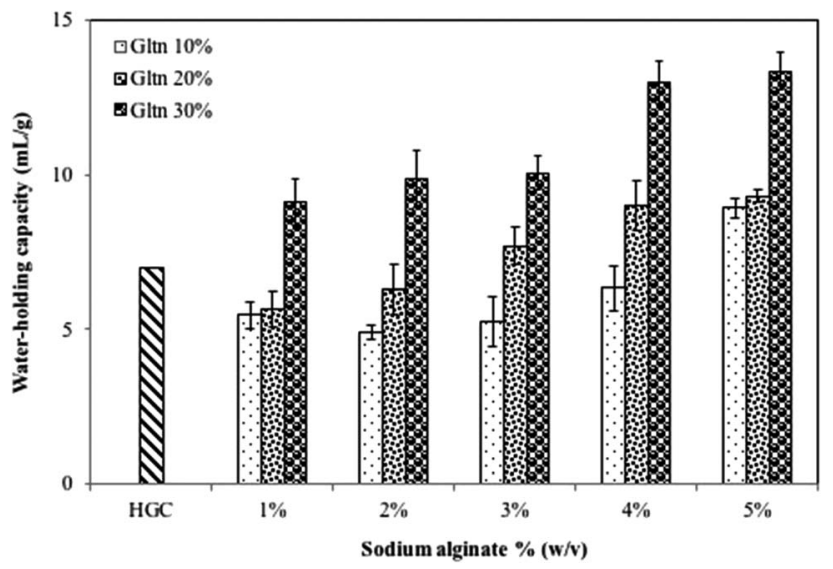

Fig. 3 Water-holding capacity of gelatin-alginate based films. Results are presented as means \pm SD of three different samples $(n=3)$.

the initial step of "return to start" and at "force in tension" modes. The probe was advanced into the capsule at a rate of $0.2 \mathrm{~mm} \mathrm{~s}^{-1}$ at various compressive strain values (\%) until the capsules were pulled apart. The force applied was recorded as a function of distance, and a graph of force $(\mathrm{g})$ against time $(\mathrm{s})$ was plotted..$^{30}$ Each capsule was measured three times and the average recorded.

\subsection{Statistical analysis}

A one-way analysis of variance (ANOVA) with a post-hoc Tukey's honestly significant difference (HSD) test was carried out to identify significant differences $(P<0.05)$ between data sets.

\section{Results and discussion}

Hard capsules usually require between one and four excipients while some five to eight are needed in tablet formulation. ${ }^{31}$ In the current study the four excipients were gelatin, sodium alginate, $\mathrm{PEG}$ and $\mathrm{TiO}_{2}$. Different concentrations of gelatin and sodium alginate were formulated in order to obtain a hard capsule shell and the results are as shown in Table 1. Although with all formulations film strips were produced, only formulation numbers $4,7,8,11$ and 12 were able to produce hard capsule shells via a manual dipping process. The $\mathrm{pH}$ of the mixed solutions in all formulations were acidic ( $\mathrm{pH}$ 5.4-5.9). Although changes in $\mathrm{pH}$ values were very small, capsules were only obtained at pH 5.6.

With an increased concentration of sodium alginate (from $1 \%$ to $5 \%$ ) the $\mathrm{pH}$ of the mixture also increased, which confirmed the role of sodium alginate in changing the $\mathrm{pH}$ of the mixture due to the presence of an acidic group, such as carboxylic acid in alginate chains. Sodium alginate and PEG are classified as smart polymers or as stimuli-responsive, which could possibly demonstrate marked physiochemical changes arising from small environmental changes, such as temperature, $\mathrm{pH}$, light, magnetic field, ionic factors, etc.

The moisture content of the film strips is shown in Table 1. The moisture content increased with an increased percentage of gelatin and decreased with an increased percentage of sodium alginate. It has been reported that hydrocolloid films prepared from, for example, sodium alginate are strong but of poor quality due to their hydrophilic nature..$^{32,33}$ Potentially gelatin, a protein, which as a film is very transparent, would be an excellent oxygen and carbon dioxide barrier. However the mechanical properties of these films are vulnerable to higher water content. Nevertheless, the addition of corn starch, ${ }^{34}$ alginate $^{35}$ or pectin ${ }^{36}$ considerably improved the quality of the gelatin films. From the observation that formulation numbers $4,7,8,11$ and 12 were able to form a hard shell, the base mixture from these formulations will be further analysed as follows:

Rheological characteristic of the base mixture from formulations 4, 7, 8, 11 and 12 are shown in Fig. 1. The rheological properties of the mixture, such as viscosity and elasticity, are affected by some parameters: viz. mixing ratio, $\mathrm{pH}$, type of gelatin and ionic strength. ${ }^{37}$ Gelatin is a soluble protein compound obtained by partial hydrolysis of collagen, and it is the main fibrous protein constituent in bones, cartilages and skin; hence the source, age of animal, and type of collagen are all intrinsic factors influencing the properties of the gelatins. Due to different collagen sources and different methods of extraction and processing, the physiochemical properties of such animal-derived gelatin exhibited significant differences in the characteristics and performance of gelatin. Gelatin quality for a particular application depended largely on its rheological properties. Apart from its basic physicochemical properties, viz.

Table 2 Color and transparency values of films prepared from different concentrations of sodium alginate and gelatin ${ }^{a}$

\begin{tabular}{|c|c|c|c|c|c|}
\hline \multirow[b]{2}{*}{ Sample } & \multicolumn{3}{|c|}{ Hunter color parameters } & \multirow[b]{2}{*}{$\Delta E$} & \multirow[b]{2}{*}{ WI } \\
\hline & $L$ & $a$ & $b$ & & \\
\hline HGC & $26.7 \pm 1.2^{\mathrm{f}}$ & $0.06 \pm 0.05^{\mathrm{a}}$ & $0.1 \pm 0.2^{\mathrm{d}}$ & $70.8 \pm 1.2^{\mathrm{a}}$ & $27.1 \pm 1.3^{\mathrm{f}}$ \\
\hline $\mathrm{F}_{4}$ & $52.6 \pm 0.6^{\mathrm{e}}$ & $-1.1 \pm 0.1^{\mathrm{b}}$ & $-3.9 \pm 0.6^{\mathrm{f}}$ & $44.9 \pm 0.6^{\mathrm{b}}$ & $40.8 \pm 2.9^{\mathrm{e}}$ \\
\hline $\mathrm{F}_{7}$ & $54.6 \pm 0.5^{\mathrm{d}}$ & $-1.7 \pm 0.1^{\mathrm{c}}$ & $-0.9 \pm 0.1^{\mathrm{e}}$ & $42.9 \pm 0.5^{\mathrm{c}}$ & $51.9 \pm 0.7^{\mathrm{d}}$ \\
\hline $\mathrm{F}_{8}$ & $57.9 \pm 1.6^{\mathrm{c}}$ & $-1.9 \pm 0.2^{\mathrm{d}}$ & $3.5 \pm 0.8^{\mathrm{c}}$ & $39.8 \pm 1.5^{\mathrm{d}}$ & $68.4 \pm 1.2^{\mathrm{c}}$ \\
\hline$F_{11}$ & $62.9 \pm 1.2^{\mathrm{b}}$ & $-2.5 \pm 0.1^{\mathrm{e}}$ & $3.8 \pm 0.2^{\mathrm{b}}$ & $34.9 \pm 1.2^{\mathrm{e}}$ & $74.3 \pm 1.0^{\mathrm{b}}$ \\
\hline $\mathrm{F}_{12}$ & $63.98 \pm 1.0^{\mathrm{a}}$ & $-2.4 \pm 0.1^{\mathrm{e}}$ & $3.99 \pm 0.4^{\mathrm{a}}$ & $33.6 \pm 1.0^{f}$ & $75.9 \pm 1.9^{\mathrm{a}}$ \\
\hline
\end{tabular}

${ }^{a}$ Mean $\pm \mathrm{SD}(n=3)$, values with different superscript letters (a, b, c, d, e and $\left.\mathrm{f}\right)$ in the same column are significantly different $(P<0.05)$. 


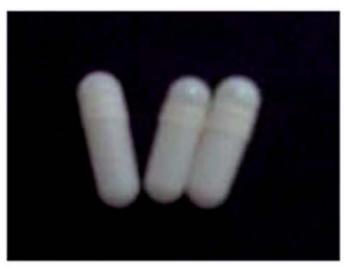

F4

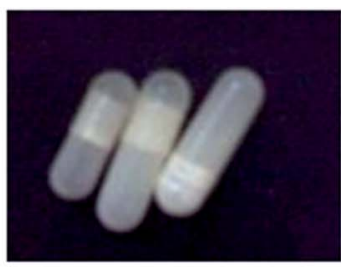

F7

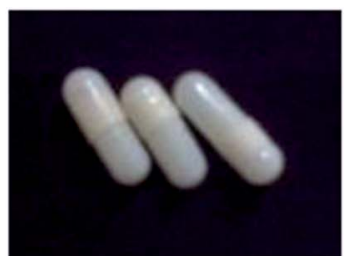

F8

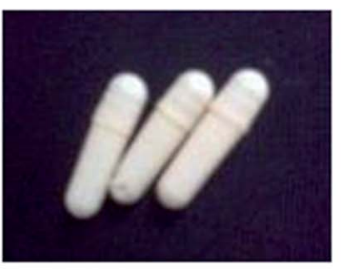

F11

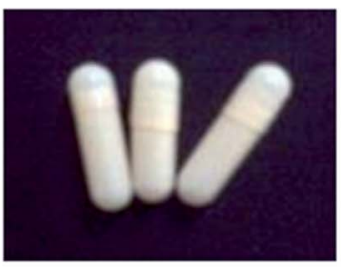

F12

Fig. 4 Capsule shells obtained from formulation $4\left(F_{4}\right)$, formulation $7\left(F_{7}\right)$, formulation $8\left(F_{8}\right)$, formulation $11\left(F_{11}\right)$ and formulation $12\left(F_{12}\right)$.

composition parameters, solubility, transparency, color, odour and taste, the main attributes that best define the overall commercial quality of gelatin are gel strength and thermal stability. Gel strength and thermostability are largely dependent on the molecular properties of gelatin, especially with respect to two main factors: (i) the amino acid composition which is species-specific and (ii) the molecular weight distribution which arises mainly from processing conditions. The physical properties of gelatin influence its quality and potential applications, since they are related to the structure of gelatin. Gelatins of various gel strengths are suitable for various soft gelatin and hard gelatin capsule applications. ${ }^{38}$

The viscosities of the mixtures with different concentrations of sodium alginate and gelatin at different ranges of shear rates $\left(0.1,1,10,100\right.$ and 1000) $\mathrm{s}^{-1}$ are as shown in Fig. 1(a-c). Increasing the concentration of sodium alginate (from $1 \%$ to $5 \%$ ) increased the viscosity by about four times. There was a significant difference $(P<0.05)$ between the viscosity of the mixture in $10 \%, 20 \%$ and $30 \%$ gelatin, with the highest viscosity in a mixture containing $30 \%$ followed by $20 \%$ and $10 \%$ gelatin. It has been reported that sodium alginate and gelatin considerably improved the viscoelasticity of the gels to evolve good film-forming properties. ${ }^{3,39,40}$ In response to the shear rate

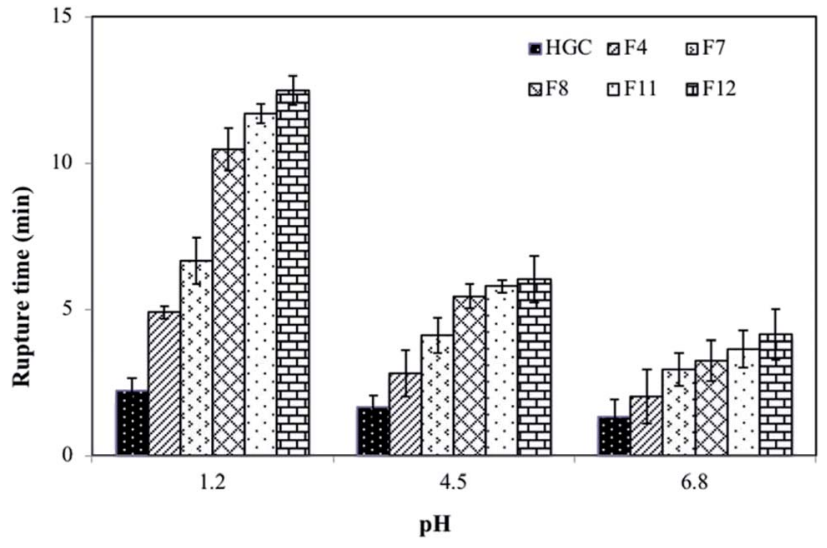

Fig. 5 Capsule shell rupture times in different dissolution media. Values are given as means \pm SD taken from three different samples ( $n$ $=3$ ).

effect, the solutions in all three different concentrations of gelatin $(10 \%, 20 \%$ and $30 \%)$ showed the same general features, following non-Newtonian fluid characteristics, as observed from the results in Fig. 1(a-c). Shear-thinning behaviour could be the result of structural changes in the solutions as and when

Table 3 Physicochemical properties of gelatin-alginate capsule shells ${ }^{a}$

\begin{tabular}{lllll}
\hline Capsules & Thickness $(\mathrm{mm})$ & Weight $(\mathrm{g})$ & Moisture content $(\%)$ & Ash content $(\%)$ \\
\hline $\mathrm{HGC}$ & $0.21 \pm 0.03$ & $0.09 \pm 0.02$ & $13.58 \pm 0.18$ & $0.92 \pm 0.08$ \\
$\mathrm{~F}_{4}$ & $0.18 \pm 0.03^{\mathrm{e}}$ & $0.08 \pm 0.01^{\mathrm{e}}$ & $5.5 \pm 0.18^{\mathrm{e}}$ & $1.58 \pm 0.16^{\mathrm{e}}$ \\
$\mathrm{F}_{7}$ & $0.28 \pm 0.06^{\mathrm{d}}$ & $0.11 \pm 0.03^{\mathrm{d}}$ & $7.03 \pm 0.02^{\mathrm{c}}$ & $1.87 \pm 0.25^{\mathrm{d}}$ \\
$\mathrm{F}_{8}$ & $0.33 \pm 0.08^{\mathrm{c}}$ & $0.15 \pm 0.02^{\mathrm{c}}$ & $6.63 \pm 3.03^{\mathrm{d}}$ & $3.27 \pm 0.69^{\mathrm{c}}$ \\
$\mathrm{F}_{11}$ & $0.37 \pm 0.06^{\mathrm{b}}$ & $0.16 \pm 0.03^{\mathrm{b}}$ & $10.6 \pm 0.72^{\mathrm{a}}$ & $3.86 \pm 0.26^{\mathrm{b}}$ \\
$\mathrm{F}_{12}$ & $0.47 \pm 0.18^{\mathrm{a}}$ & $0.25 \pm 0.11^{\mathrm{a}}$ & $7.37 \pm 0.23^{\mathrm{b}}$ &
\end{tabular}

${ }^{a}$ Means $\pm \mathrm{SD}(n=3)$; values with different superscript letters (a, b, c, d and e) in the same column are significantly different $(P<0.05)$. 
Table 4 Compression force values for different formulation of hard capsule shells after $2 \mathrm{~s}^{a}$

\begin{tabular}{lc}
\hline Sample & Compression force value $(\mathrm{g})$ \\
\hline Commercial HGC & $1221.0 \pm 147.5^{\mathrm{a}}$ \\
$\mathrm{F}_{4}$ & $1234.8 \pm 166.7^{\mathrm{a}}$ \\
$\mathrm{F}_{7}$ & $1209.6 \pm 148.1^{\mathrm{b}}$ \\
$\mathrm{F}_{8}$ & $1121.3 \pm 109.0^{\mathrm{b}}$ \\
$\mathrm{F}_{11}$ & $949.1 \pm 242.8^{\mathrm{c}}$ \\
$\mathrm{F}_{12}$ & $878.3 \pm 117.6^{\mathrm{c}}$ \\
${ }^{a}$ Means $\pm \mathrm{SD}(n=5) ;$ values with different superscript letters $(\mathrm{a}, \mathrm{b}$ and \\
$\mathrm{c})$ are significantly different $(P<0.05)$.
\end{tabular}

the shear rate is altered. The asymmetrical molecules in the solute viscosity are very much dependent on the orientation of the molecules. With increased shear rate the molecules will be aligned in the direction of flow, which reduces the apparent viscosity. ${ }^{\mathbf{4 1}}$

FTIR spectra were used to confirm the chemical functional group of gelatin and sodium alginate-gelatin blends and the results are shown in Fig. 2. Absorption observed at $\sim 920 \mathrm{~cm}^{-1}$ corresponded to the $\mathrm{C}-\mathrm{H}$ group. The band in the region of $\sim 1100 \mathrm{~cm}^{-1}$ was assigned to the $\alpha$-glycosidic bond. ${ }^{42}$ It was also reported that bands around $1200 \mathrm{~cm}^{-1}$ to $1000 \mathrm{~cm}^{-1}$ are due to $\mathrm{C}-\mathrm{OH}$ bonds, an indication of the presence of oligosaccharides. ${ }^{43}$ Additionally peaks in the range of $\sim 950-1200 \mathrm{~cm}^{-1}$ indicated the presence of polysaccharides. ${ }^{44}$ Having the wavelength within range enabled the major chemical group in the polysaccharides to be identified. This identification in turn revealed the position and intensity of the bands specific to each polysaccharide. ${ }^{45}$ The peak at $\sim 1430 \mathrm{~cm}^{-1}$ is due to asymmetrical stretching of COO-, which is linked to the hydrogen of the alginate. Absorption at $\sim 1537 \mathrm{~cm}^{-1}$ was attributed to $\mathrm{C}-\mathrm{N}$ stretching. ${ }^{46}$ The peak intensity at $\sim 1639 \mathrm{~cm}^{-1}$ is characteristic of the $-\mathrm{CONH}_{2}$ group, which indicated that the alginate's negative group is in all probability associated with gelatin's positive load. ${ }^{47}$ Increased peak intensity at $1630 \mathrm{~cm}^{-1}$, which corresponded to $\mathrm{CONH}_{2}(\mathrm{C}=\mathrm{O})$, could indicate that the alginate's negative group could be associated with gelatin's positive load. This observation is suggestive of intermolecular interactions between alginate and gelatin, which thus provide conclusive evidence of good molecular compatibility between the two polymers, which will improve its mechanical properties. $^{48}$ The band in the region of $\sim 2920 \mathrm{~cm}^{-1}$ was attributed to the $\mathrm{C}-\mathrm{H}$ stretching vibration, which was regarded as characteristic of the absorption of polysaccharides. ${ }^{49}$ FTIR spectra of gelatin and gelatin-sodium alginate exhibited a peak at $\sim 3280 \mathrm{~cm}^{-1}$, $(\mathrm{O}-\mathrm{H})$ vibration due to the presence of a large amount of water. ${ }^{50}$ By virtue of the presence of carboxylic and amino guanidine groups, gelatin is amphoteric in nature. At acidic $\mathrm{pH}$, gelatin will have a net positive charge and will therefore be able to form a complex with anionic polysaccharides, such as the alginate, through electrostatic interactions, ${ }^{51}$ leading to the formation of a polyelectrolyte complex. $^{52}$
Water-holding capacity (WHC) is a functional property which is closely related to interactions between water and other gelatin components. ${ }^{24}$ The WHC of gelatin-alginate films are shown in Fig. 3. There are significant differences $(P<0.05)$ among the WHC for all formulations with different concentrations of sodium alginate and gelatin. Increased gelatin concentration from $10 \%$ to $30 \%$ and sodium alginate from $1 \%$ to $5 \%$ increased the WHC in this study. The highest WHC $\left(13.36 \mathrm{~mL} \mathrm{mg}^{-1}\right)$ was observed in films containing $30 \%$ gelatin mixed with $5 \%$ sodium alginate, whereas a lower concentration of sodium alginate and gelatin exhibited a lower WHC $\left(4.9 \mathrm{~mL} \mathrm{mg}^{-1}\right)$. Gelatin's WHC is affected by the amount of hydrophilic amino acids and is due to capillary forces. ${ }^{53}$ Following gelation, in spite of the water molecules being trapped in the matrix, the alginate matrix retained the ability to migrate, which constitutes an important factor in many applications. ${ }^{\mathbf{1 1}}$

One important quality parameter for potential industrial applications of the films is color evaluation. ${ }^{54}$ Color evaluations by observation of $\Delta E^{*}$ (variation in the color parameter), $a^{*}$ value (redness/greenness), $b^{*}$-value (yellowness/blueness), $L^{*}$ value (lightness) and whiteness index (WI*) for the films based on different concentrations of gelatin and sodium alginate blends are presented in Table 2 . There is a significant difference $(P<0.05)$ between the $L^{*}$-values in all films. $L^{*}$-values in all formulations are higher than that of HGC used as a control. An increased concentration of gelatin and sodium alginate showed a lowering of the $a^{*}$-value, with increases in $L^{*}, b^{*}, \Delta E^{*}$-values and WI. Positive values of $b^{*}$ indicate a yellow coloration, which could be associated with the yellowish color of sodium alginate, which had a direct effect on the color of the resulting films. The control films without the addition of sodium alginate (HGC) were translucent. When gelatin solutions were added to higher concentrations of sodium alginate, the films formed were tinted milk-white, as can be seen in Fig. 4. It was observed that the opacity and transparency of the selected films (used for capsule formation) depended on the concentration of gelatin and sodium alginate; the greater the thickness, the more opaque the film and subsequent capsule appearance. Results from this study concurred with those of ref. 55 , where the color parameter values were dependent on the film thickness.

The physical properties of the capsule shells are shown in Table 3. The quantity of blend picked up by the pins is dependent upon the viscosity of the solution and the speed of the pins. Too high a viscosity and the pin speed will lead to capsules with a greater wall thickness than normal. The hard capsule shell is usually thinnest on the shoulder and thickest at the rounded ends. Thickness, which is dependent on the nature and composition of the shell, increased with increased concentration of gelatin and sodium alginate. There are significant differences $(P<0.05)$ between variations in the thickness and weight of the capsule shells in all formulations. The weight of the capsule shell ranged between $0.080 \mathrm{~g}$ and $0.25 \mathrm{~g}$. It has been reported that the thickness and uniformity of the capsules are dependent on the dipping temperature and viscosity of the capsule base material. Capsule thickness could have a possible influence on filling, which may require modifications to the standard automated filling machines. ${ }^{56}$ 
The amount of water present in the films provides an indication of the hydrophobicity of the films, ${ }^{57}$ which strongly affects the physical characteristics of the capsules. Storage conditions or moisture transfer between capsule shells could vary the moisture content of the capsule shells. The latter invariably led to the capsule becoming brittle or sticky and these are considered undesirable physical properties for a capsule shell. ${ }^{58}$ Following manufacture, the moisture content should be at a certain desirable level if the capsule shells are to behave satisfactorily in high-speed capsule filling machines. Below or above certain levels, the capsule becomes brittle and could easily break, releasing the contents and changing the stability of the capsule. The moisture content of gelatin-sodium alginate capsules in this study, as observed in Table 3, is between $5 \%$ and $11 \%$. Gelatin contains a wide range of hydrophilic amino acids; ${ }^{59}$ hence films with higher concentrations of gelatin-sodium alginate ratio $\left(\mathrm{F}_{11}>\mathrm{F}_{12}>\mathrm{F}_{7}>\mathrm{F}_{8}>\mathrm{F}_{4}\right)$, as in this study, could possibly hold higher amounts of water. Generally, films with a higher protein content are more likely to be hygroscopic compared to those with a lower protein content. ${ }^{60} \mathrm{It}$ has been reported that the moisture content of gelatin capsules at $15 \%$ was higher than that of HPMC plant-based capsules at $5 \% .{ }^{61}$ As the gelatin-sodium alginate capsules in this study are the product of gelatin and plant-based gelling agent (sodium alginate), in all probability the range of moisture content (5$11 \%$ ) is between those of gelatin and plant-based capsules. Overall, the final thickness, as well as the water content of the films, varied, which thus explained the differences in mechanical properties.

The ash content of the capsule shells is considered safe and fulfils the quality control requirement, as it is below $5 \%$ $(<2 \%$ for transparent capsules and $<5 \%$ for opaque capsules). ${ }^{62}$ Ash percentage, which is an indication of mineral content, was highest for formulation $12(4.05 \%)$ but below the maximum for opaque capsules; formulation 4 exhibited the lowest ash content $(1.58 \%)$. Ash content for all the formulations was below $5 \%$, which is the maximum content for opaque capsules.

Fig. 5 shows the rupture time of different capsule formulations subjected to acetate buffer $(\mathrm{pH} 4.5)$, phosphate buffer ( $\mathrm{pH}$ 6.8) and SGF ( $\mathrm{pH} 1.2$ ). There were significant differences $(P<0.05)$ between the rupture times in three different solutions. The sensitivity of the capsule at $\mathrm{pH} 7$ is higher than that at acidic $\mathrm{pH}$. The high $\mathrm{pH}$ is associated with a higher degree of dissociation of carboxylic acid groups of alginate at neutral $\mathrm{pH} .{ }^{63}$ With increased repulsion between the ionized carboxylate groups, the water uptake capacity of the films also increased, due to expansion of the network. The highest rupture times were observed with SGF ( $\mathrm{pH} 1$ ) for all formulations. The rupture time in an HGC capsule without sodium alginate, however, is lower ( $<5 \mathrm{~min})$ in all tested dissolution media. Ref. 2 and 64 reported that plant-based capsules such as HPMC showed slower rupture times compared to gelatinbased HGC.

Due importance should be given to the mechanical properties of the capsule shell. This is from the perspective that throughout its life cycle, damage could possibly occur during large-scale filling, packaging, and handling. To avoid premature rupture resulting in the release of its contents, the capsule shell should be designed to provide adequate mechanical strength. ${ }^{65}$ It has been reported that the level of force measured by the instrument is very much dependent on the rate of deformation. ${ }^{66}$ Results of compression and tension tests on capsule shells after $2 \mathrm{~s}$ are as shown in Table 4. There is no significant difference $(P>0.05)$ between formulation 4 and that of a commercial HGC capsule shell. Increasing the concentration of gelatin decreased the resilience of the capsule to force, but increasing the concentration of sodium alginate had no such effect. However, there are significant differences $(P<0.05)$ between formulations 11,12 and 7,8 and commercial HGC.

\section{Conclusion}

Results from this study revealed that the gelatin/sodium alginate ratio in the preparation of films plays a significant role in their physical and chemical properties. This ratio strongly influenced the viscosity of the film-forming suspensions, which may affect retraction of the network during film drying and influence the final thickness. Thickness influences the physicochemical properties of capsule shells, such as color and transparency, water-holding capacity, strength and rupture time. Although gelatin-sodium alginate blends demonstrated good film-forming properties, from the perspective of commercial production, hard capsule shells need further investigation, especially into the aspect of filling with a wide range of drugs. More importantly, a comprehensive in vivo study is required to categorically substantiate their viability in the digestive tract. Although the results of in vitro studies at times allow the prediction of in vivo behaviour, there are instances when no in vitro/in vivo correlation exists. Biopharmaceutical evaluations of new formulations are therefore important right from the onset of the study. Studies with respect to influencing factors on capsule performance should be optimized using response surface methodology; the effect of other parameters, such as type and viscosity grades of sodium alginate and different polymer ratios, on the drug release rates and absorption rates should also be considered. Furthermore, the data obtained from physicochemical properties could be comprehended by evaluating the micro-structure properties using scanning electron microscopy. Due to variability in gelatin source material and methods of extraction and processing, the physicochemical properties of such animal-derived gelatin preparations exhibit significant variability in characteristics and correspondingly in performance, which should be considered in future work.

\section{Conflicts of interest}

There is no competing interest as declared by authors.

\section{Acknowledgements}

This work was funded by Universiti Putra Malaysia under UPM Short Term Grant (UPM/700-2/1/GP-IPS/2015/9460800). 


\section{References}

1 M. C. Gomez-Guillen and P. Montero, J. Food Sci., 2001, 66, 213-216.

2 Y. Chen, Z. Huiying, L. Xianwu, L. Zusen, L. Bin, W. Jiande, S. Mengzuan, N. Willen and L. Yuan, Carbohydr. Polym., 2016, 143, 262-269.

3 C. Bednarz, B. Ma, J. Kasica, M. Okoniewska, and Z. Li, Hard capsules, US 20050196437 A1, 2005.

4 R. C. Rowe, P. S. Shskey and P. Weller, Handbook of pharmaceutical excipients, J. Pharmaceutical Press/American Pharmacists Association, 2003.

5 S. K. Cole, M. J. Story, D. Attwood, T. Laudanski, J. Robertson and S. G. Barnwell, Int. J. Pharm., 1992, 88, 211-220.

6 S. M. Liebowitz, W. A. Vadino and T. J. Ambrosio, Drug Dev. Ind. Pharm., 1990, 16, 995-1010.

7 M. S. Ku, Q. Lu, W. Li and Y. Chen, Int. J. Pharm., 2011, 416, 16-24.

8 S. F. Hosseini, M. Rezaei, M. Zandi and F. Farahmandghavi, Food Hydrocolloids, 2015, 44, 172-182.

9 M. García, M. Martino and N. Zaritizky, J. Food Sci., 2000, 65, 941-947.

10 A. Jongjareonrak, S. Benjakul, W. Visessanguan and M. Tanaka, Eur. Food Res. Technol., 2006, 222, 650-657.

11 H. H. Tønnesen and J. Karlsen, Drug Dev. Ind. Pharm., 2002, 28, 621-630.

12 S. J. Kim, S. G. Yoon and S. I. Kim, J. Appl. Polym. Sci., 2004, 91, 3705-3709.

13 A. P. Rokhade, S. A. Agnihotri, S. A. Patil, N. N. Mallikarjuna, P. V. Kulkarni and T. M. Aminabhavi, Carbohydr. Polym., 2006, 65, 243-252.

14 C. Xiao, H. Liu, Y. Lu and L. Zhang, Pure Appl. Chem., 2001, 38, 317-328.

15 N. Segi, T. Yotsuyanagi and K. Dceda, Chem. Pharm. Bull., 1989, 37, 3092-3095.

16 Y. Mürata, K. Nakada, E. Miyamoto, S. Kawashima and S.-H. Seo, J. Control. Release, 1993, 23, 21-26.

17 K. Tateshita, S. Sugawara, T. Imai and M. Otagiri, Biol. Pharm. Bull., 1993, 16, 420-424.

18 M. F. Lu, L. Woodward and S. Borodkin, Drug Dev. Ind. Pharm., 1991, 17, 1987-2004.

19 J. Zatz and D. Woodford, Drug Dev. Ind. Pharm., 1987, 13, 2159-2178.

20 N. N. Sabil, M. A. El-Menshawy and A. A. Ismail, Pharm. Ind., 1987, 40, 1230.

21 A. Badwan, A. Abumalooh, E. Sallam, A. Abukalaf and O. Jawan, Drug Dev. Ind. Pharm., 1985, 11, 239-356.

22 T. J. Gutiérrez, M. S. Tapia, E. Pérez and L. Famá, Starch Stärke, 2014, 66, 1-8.

23 M. Gogna and R. E. Goacher, Bioresources, 2018, 13, 846-860.

24 G. Ninan, J. Joseph and Z. A. A. Aliyamveettil, J. Food Sci. Technol., 2014, 51, 2085-2091.

25 F. M. Diniz and A. M. Martin, Food Sci. Technol., 1997, 30, 266-272.

26 P. B. Pathare, U. L. Opara and F. A. Al-Said, Food Bioprocess Technol., 2013, 6, 36-60.
27 AOAC, Official Methods of Analysis, Association of Official Analytical Chemists, Arlington, VA, USA, 18th edn, 2005.

28 H. J. Bae, D. S. Cha, W. S. Whiteside and H. Park, J. Food Chem., 2008, 106, 96-105.

29 S. Woraharn, C. Chaiyasut, B. Sirithunyalug and J. Sirithunyalug, Afr. J. Microbiol. Res., 2010, 4, 2086-2093.

30 X. Mei, F. Etzler and Z. Wang, Int. Pharm. J., 2006, 324, 128135.

31 S. Stegemann, Hard gelatin capsules today and tomorrow, Capsugel Library, 2002, pp. 1-23.

32 J. J. Kester and O. R. Fennema, Food Technol., 1986, 40, 4759.

33 A. Syarifuddin, Hasmiyani, A. Dirpan and M. Mahendradatta, IOP Conf. Ser. Earth Environ. Sci., 2017, 101, 1-9.

34 F. M. Fakhouri, S. M. Martelli, T. Caon, J. I. Velasco and L. H. I. Mei, Postharvest Biol. Technol., 2015, 109, 57-64.

35 Z. Dong, Q. Wang and Y. Du, J. Membr. Sci., 2006, 280, 37-44. 36 M. Rezvanian, N. Ahmad, M. C. I. M. Amin and N. ShiowFern, Int. J. Biol. Macromol., 2017, 97, 131-140.

37 Y. Toyama, R. Sahara, Y. Lino and K. Kubota, Trans. Mater. Res. Soc. Jpn, 2011, 36, 383-386.

38 M. C. Gómez-Guillén, B. Giménez, M. E. López-Caballero and M. P. Montero, Food Hydrocolloids, 2011, 25, 1813-1827.

39 S. R. Derkach, S. O. Ilyin, A. A. Maklakova, A. G. Kulichikhin and A. Y. Malki, LWT-Food Sci. Technol., 2015, 63, 612-619.

40 Y. Pranoto, C. M. Lee and H. J. Park, LWT-Food Sci. Technol., 2006, 40, 766-774.

41 A. M. Elfak, G. Pass and G. O. Phillips, J. Sci. Food Agric., 1979, 30, 439-444.

42 P. Capek, M. Drábik and J. Turjan, J. Therm. Anal. Calorim., 2010, 99, 667-673.

43 M. K. Baseri and S. Baker, Biophys. J., 2011, 21, 277-284.

44 B. Bello, M. Shuhaimi, T. J. Shun, T. A. T. Ibrahim, T. Y. Joon, A. B. Ariff, M. Y. Manap and S. Abbasiliasi, 3 Biotech, 2018, 8, 346.

45 A. Synytsya, K. Mícková, A. Synytsya, I. Jablonský, J. Spěváček, V. Erban and J. Čopíková, Carbohydr. Polym., 2009, 76, 548-556.

46 V. Asyana, F. Haryanto, L. A. Fitri, T. Ridwan, F. Anwaryand and H. Soekersi, J. Phys.: Conf. Ser., 2016, 694.

47 S. Lopes, L. Bueno, F. A. Júnior and C. Finkler, An. Acad. Bras. Cienc., 2017, 89, 1601-1613.

48 N. Cebi, M. Z. Durak, O. S. Toker, O. Sagdic and M. Arici, Food Chem., 2016, 190, 1109-1115.

49 R. Tripathi and B. Mishra, AAPS PharmSciTech, 2012, 13, 1091-1102.

50 G. G. D. Silva, P. J. A. Sobral, R. A. Carvalho, P. V. A. Bergo, O. Mendieta- Taboada and A. M. Q. B. Habitante, J. Polym. Environ., 2008, 16, 276-285.

51 M. Saravanan and K. P. Rao, Carbohydr. Polym., 2010, 80, 808-816.

52 S. Nualkaekul, M. T. Cook, V. V. Khutoryanskiy and D. Charalampoulos, Food Res. Int., 2013, 53, 304-311.

53 A. Haddar, A. Bougatef, R. Balti, N. Souissi, W. Koched and M. Nasri, J. Food Nutr. Res., 2011, 50, 150-159. 
54 I. Sifuentes-Nieves, R. Rendon-Villalobos, A. JimenezAparicio, B. H. Camacho-Díaz, G. F. Gutierrez Lopez and J. Solorza-Feria, Int. J. Polym. Sci., 2015, 2015, 1-8.

55 S. Mali, L. B. Laram, L. Pereira Ramos and M. V. E. Grossmann, J. Agric. Food Chem., 2004, 52, 77207725.

56 A. M. Smith, A. Inghamb, L. M. Grovera and Y. Perrieb, J. Pharm. Pharmacol., 2010, 62, 1-6.

57 K. Mia, E. G. Ivona, T. B. Marina, Š. Mario, D. U. Verica and G. Kata, Food Hydrocolloids, 2018, 84, 238-246.

58 R. K. Chang, K. S. Raghavan and M. A. Hussain, J. Pharm. Sci., 1998, 87, 556-668.

59 S. M. Cho, K. S. Kwak, D. C. Park, Y. S. Gu, C. I. Ji and D. H. Jang, Food Hydrocolloids, 2004, 18, 573-579.
60 P. Kaewprachu, K. Osako, S. Benjakul and S. Rawdkuen, J. Food Sci. Technol., 2016, 53, 2083-2091.

61 M. Ciper and R. Bodmeier, Eur. J. Pharm. Biopharm., 2006, 62, 178-184.

62 G. Rajkumar, Int. J. Drug Regul. Aff., 2014, 2, 32-36.

63 A. Mohanan and B. Vishalakshi, Int. J. Polym. Mater., 2009, 58, 561-580.

64 M. S. Ku, W. Li, W. Dulina, F. Donahue, D. Cade, H. Benameur and K. Hutchisonc, Int. J. Pharm., 2010, 386, 30-41.

65 S. Missaghi and R. Fassihi, Drug Dev. Ind. Pharm., 2006, 32, 829-838.

66 M. Kuentz and D. Röthlisberger, Int. J. Pharm., 2002, 236, 145-152. 